\title{
Post disaster reconstruction activities: a case study in Ghana
}

\author{
K. Adu-Boateng \& B. M. Oppong \\ Community Based Rural Development Project (CBRDP), Ghana
}

\begin{abstract}
Ghana experienced heavy rains between August and September, 2007. In addition to the heavy rains experienced in the country, the Government of Burkina Faso also opened the Bagre dam in that country. Some parts of the three Northern regions (Upper West, Upper East and Northern) were affected by flash floods. The World Bank focused mainly on the reconstruction of public infrastructure and capacity building of relevant stakeholders that were involved in the reconstruction activities through the Northern Floods Reconstruction Programme (NFRP) under the Community Based Rural Development Project (CBRDP), funded by the World Bank and Agence Francaise De Development (AFD). The amount involved in the programme was $\$ 6,500,000.00$ from the World Bank-IDA and \$ 1,300,000.00 from the International Fund for Agriculture Development (IFAD) through the Northern Region Poverty Reduction Programme (NORPREP). However, the overall cost of public infrastructure was estimated at $\$ 125,000,000.00$. The overall management of the programme was done by the World Bank.

The paper seeks to present the key features of the programme in terms of design, strategy, implementation and monitoring. It attempts to address how: (i) Local Government structures in Ghana's decentralization system were used in the implementation of the programme; (ii) an empirical formula developed to allocate the limited funds for the reconstruction activities; (iii) effective procurement methods employed without violating the World Bank and Ghana Government procurement procedures; (iv) the use and involvement of existing Institutions; and (v) the use of Rapid Result Approach (RRA) (where damaged infrastructure were reconstructed within 100 days).
\end{abstract}

Keywords: post disaster, public infrastructure, reconstruction activities, local government structures, procurement methods, rapid results approach. 


\section{Introduction}

The August, 2007 flash floods in Ghana, affecting in particular the three northern regions, caused a humanitarian situation, the scale of which the country has not experienced in many years, if ever.

The existing Government mechanisms, the resilience of the people and the tradition of the extended family system, contributed to limit the ill-effects of large displacement to people caused by the floods. However, the damage to crops, assets and livelihood, together with the environmental effects of stagnant and receding water provided the ingredients for a potential disaster for a population that is already vulnerable, placed them even further at risk.

According to the Assessment report of 2007, initial figures indicated that 260,000 people living in the three northern regions of the country were affected. In all 29 Administrative Districts were affected by the floods. Even though these figures, as in most emergencies are crude and preliminary, the immediate needs were obvious; food, access to safe drinking water and mosquito nets. Also, there was still a need for shelter in specific areas where people were staying out in the open air or in public buildings. Medium and longer term needs included restoration of livelihood and rehabilitation of infrastructure to promote commercial activities and access to areas cut off by the floods. The livelihood issue is a combination of crops and food stocks lost in the flooding, as well as the drought experienced earlier this year. Additionally, there was a continuous erosion of household assets with a negative spiral of debt as indicated by the field assessment after the floods.

In order to address the above-mentioned immediate, medium and long-term needs as well as prevent further deterioration of the situation, a coordinated approach among all involved was promoted in the implementation of Northern Floods Reconstruction Programme (NFRP) by the Ghana Government.

\section{Areas affected by the flash floods}

The three northern regions of Ghana, namely Upper East, Upper West and Northern were affected by the 2007 flash floods. According to the Ghana local Government Act 462, there are 38 administrative districts in these three regions and 29 of them were affected. The total land area of the three northern regions is estimated at $95,000 \mathrm{~km}^{2}$ and a total estimated population of $4,000.000$, which represents about $18 \%$ of Ghana's total population and about $40 \%$ of the total land area. The affected area is shown in figure 1.

\section{Facilities and infrastructure destroyed}

The intensive nature of the floods destroyed both private and public infrastructure for social and human development, as well as farm produce. The floods destroyed cropped fields and washed away household stocks, seed stocks and livestock. The floods also destroyed point sources (boreholes and hand dug wells), domestic houses and road infrastructure. 


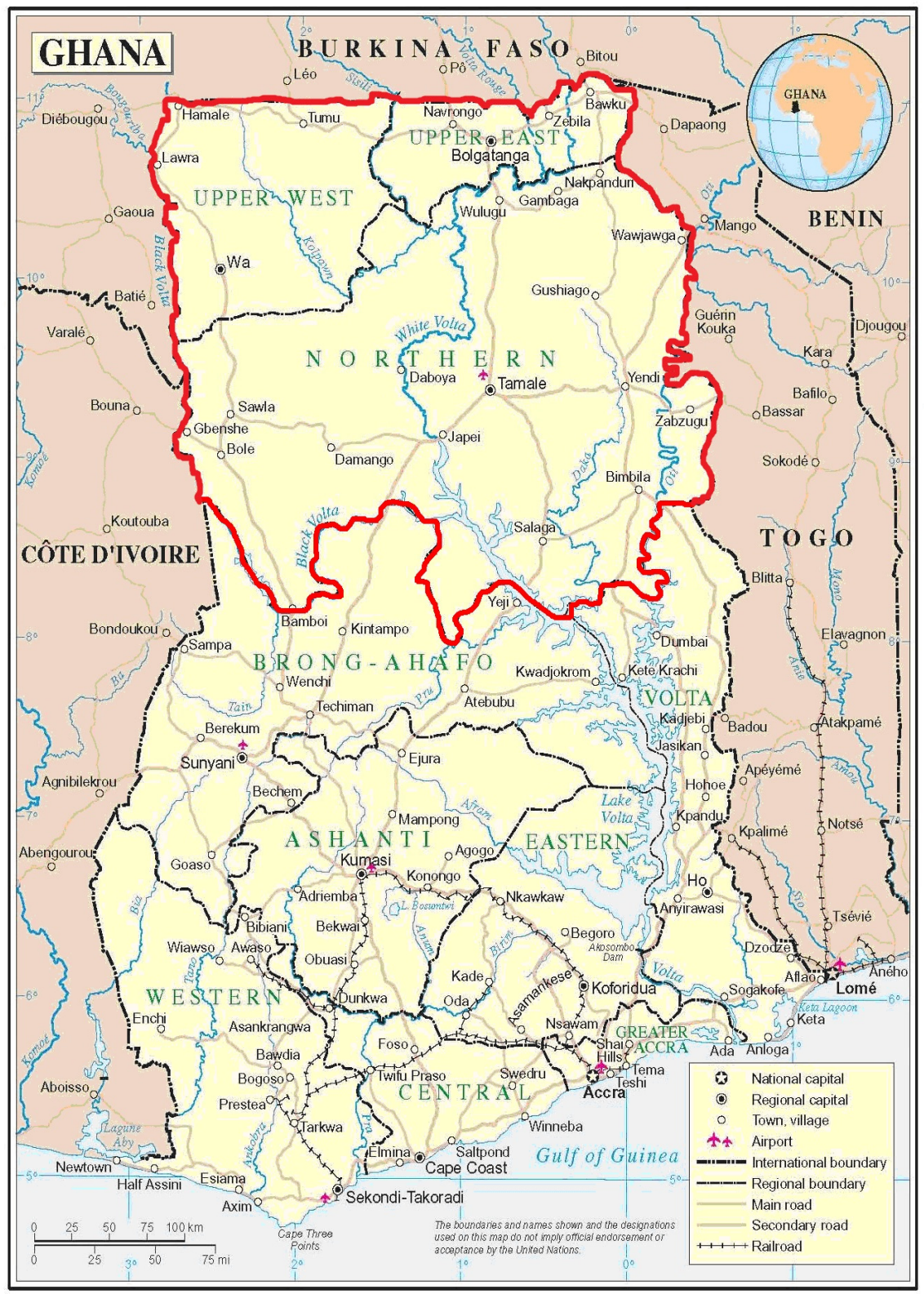

Map NO 4186 Rev 3 UNITED NATIONS

Department of Peacekeeping Operations
Catographic Section

Figure 1: $\quad$ Map of Ghana showing affected areas. 


\section{Implementation arrangement}

\subsection{Institutional structure for implementation}

Start-up workshop was organized before the commencement of the programme. The aim was to involve all stakeholders in the planning and implementation of the programme. Responsibilities and roles of the various stakeholders were discussed and agreed upon. Figure 2 gives the overall implementation arrangement of the programme.

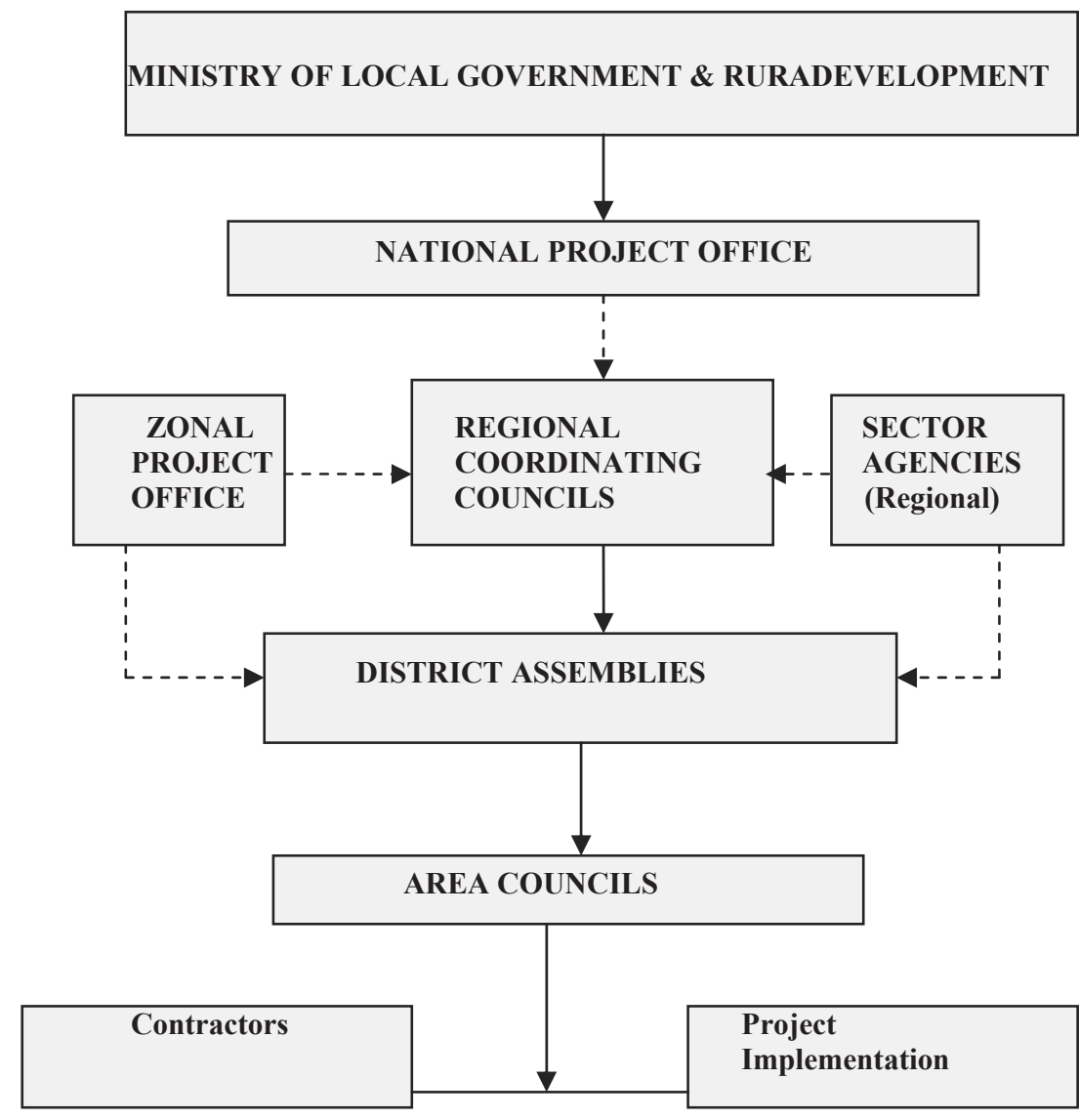

Control links

Advisory links

Figure 2: $\quad$ Implementation structure. 
The Ministry of Local Government and Rural Development (MLGRD) on behalf of the Ghana Government had the oversight responsibility of the programme. The ministry provided policy and administrative direction to the implementation of the programme. The ministry was also responsible for the monitoring and evaluation of the programme and this was made easy by the quarterly reports that were submitted by the project office to the ministry.

The CBRDP project head office provided technical support to the Regional Coordinating Councils (RCCs) and the other sector agencies in the region in the implementation of the project. The project office also served as the link between the Ministry and the implementing agencies. The CBRDP Zonal Offices and other regional agencies provided technical advice to the Regional Coordinating Council. The Regional Coordinating Council had the immediate supervisory responsibility over the District Assemblies. The RCCs coordinated and harmonized the activities of the DAs. The RCCs also reviewed and gave recommendation to the activities of the District Assemblies. The sector agencies also provided technical advice to the DAs. The District Assemblies were the direct implementers of the programme. All key decisions and activities such as the procurement processes (i.e. tender advertisement, evaluation of tenders, contract award etc) and approval for payment were done by the DAs. The DAs had supervisory role over the Area Councils, which in turn monitored the Community Implementation Committee (CIC) and the private service providers.

\subsection{Allocation of funds to district assemblies}

The overall amount needed to comprehensively repair damaged public infrastructure was estimated at over USD $\$ 100$ million, however, the funds that was made available by the World Bank and IFAD totaled USD $\$ 7,800,000$. The funds were also only to be applied to public infrastructures that were eligible under the Project Development Objectives (PDO) of CBRDP and NORPREP. Mechanism for the distribution of the funds was then developed. The criteria were based on the underlisted procedure. Details are presented in table 2.

\subsection{Procedure/steps for fund allocation}

1. The damaged infrastructures that were eligible under CBRDP/NORPREP in the affected districts were identified (column 3 of table 2). This was determined from the field assessment by stakeholders (CBRDP Annual report, 2008).

2. Identification of parameters and assigning weights depicting the relative importance of the parameters. Refer to table 2 columns (4, 5, and 6). The parameters were assigned weights totaling 10 points. This was sourced from available national data.

3. Development of a scoring scale with a range of 1 to 6 to score the six subproject types against the weighted parameters to arrive at total scores and subsequent ranking of affected Districts. 
4. The assessment matrix (table 2), was used to determine individual beneficiary DA's total scores and the relative percentage score of each DA as against the total scores of all DAs.

5. Each DA's allocation was arrived at by multiplying it's relative percentage score by total fund available ( $\$ 7.80$ million)

\subsection{Procurement procedures}

Although the programme was to be implemented under emergency conditions, procurement procedures in the recruitment of service providers were adhered to. The World Bank and Ghana Government's procurement guidelines were used concurrently. The various stages of the procurement process are presented in table 1 .

Table 1: $\quad$ Procurement processes for the disaster reconstruction activity.

\begin{tabular}{|c|c|c|c|c|}
\hline Stages & $\begin{array}{l}\text { Procurement } \\
\text { Activity }\end{array}$ & Approach & Outcome & $\begin{array}{l}\text { Average } \\
\text { time/week }\end{array}$ \\
\hline 1 & $\begin{array}{l}\text { Preparation of } \\
\text { Tenders }\end{array}$ & $\begin{array}{l}\text { Preparation of bidding } \\
\text { documents was } \\
\text { decentralized. In } \\
\text { selecting the } \\
\text { requirements, lower } \\
\text { times were chosen and } \\
\text { documents easier to be } \\
\text { obtained chosen (bid } \\
\text { securing declaration } \\
\text { was used instead of } \\
\text { bank guarantee or bid } \\
\text { bond) } \\
\end{array}$ & $\begin{array}{l}\text { Each DA } \\
\text { prepared their } \\
\text { own tender } \\
\text { documents with } \\
\text { the support of } \\
\text { the RCC and } \\
\text { Project office }\end{array}$ & 1 \\
\hline 2 & $\begin{array}{l}\text { Advertisement } \\
\text { of bids }\end{array}$ & $\begin{array}{l}\text { Central advertisement } \\
\text { was used }\end{array}$ & $\begin{array}{l}\text { This reduced } \\
\text { cost (up to 65\%) }\end{array}$ & 2 \\
\hline 3 & $\begin{array}{l}\text { Submission of } \\
\text { bids }\end{array}$ & $\begin{array}{l}\text { This activity was } \\
\text { decentralized. Bids } \\
\text { were submitted to the } \\
\text { various DAs } \\
\end{array}$ & $\begin{array}{l}\text { This allowed } \\
\text { for a lot of bids } \\
\text { to be received in } \\
\text { one day }\end{array}$ & 1 day \\
\hline 4 & $\begin{array}{l}\text { Evaluation of } \\
\text { submitted bids }\end{array}$ & $\begin{array}{l}\text { Central evaluation was } \\
\text { done. CBRDP } \\
\text { engineers all over } \\
\text { Ghana were deployed } \\
\text { for the evaluation. } \\
\text { Process was } \\
\text { supervised by RCC } \\
\end{array}$ & $\begin{array}{l}\text { This saved time } \\
\text { (up to } 70 \% \text { ) }\end{array}$ & 1 \\
\hline 5 & $\begin{array}{l}\text { Award of } \\
\text { Contracts }\end{array}$ & $\begin{array}{l}\text { This activity was } \\
\text { decentralized. }\end{array}$ & This saved time & 2 \\
\hline
\end{tabular}


Table 2: $\quad$ Funds allocated to district assembly.

\begin{tabular}{|c|c|c|c|c|c|c|c|}
\hline \multirow[b]{2}{*}{ No. } & \multirow{2}{*}{$\begin{array}{c}\text { DISTRICT } \\
\text { TOTAL } \\
\text { MAGNITUDE } \\
\text { OF SOCIO- } \\
\text { ECONOMIC } \\
\text { IMPACT }\end{array}$} & \multirow{2}{*}{$\begin{array}{c}\text { DISTRICT } \\
\text { TOTAL } \\
\text { POPULATION } \\
\text { AFFECTED }\end{array}$} & \multicolumn{2}{|c|}{$\begin{array}{c}\text { WEIGHTS TO DISTRICT } \\
\text { TOTAL AS SHARE OF } \\
\text { TOTAL } \\
\end{array}$} & \multirow{2}{*}{$\begin{array}{l}\text { DISTRICT'S } \\
\text { TOTAL } \\
\text { INDEX } \\
\end{array}$} & \multirow{2}{*}{$\begin{array}{c}\text { DISTRICT } \\
\text { ALLOCATION } \\
=\text { DA's Total } \\
\text { Index * US\$ } \\
6,800,000 \\
\end{array}$} & \multirow[b]{2}{*}{ RANKING } \\
\hline & & & $\begin{array}{l}\text { ECONOMIC } \\
\text { IMPACT } \\
\end{array}$ & $\begin{array}{c}\text { POPULATION } \\
\text { AFFECTED }\end{array}$ & & & \\
\hline D1 & 1,152 & 34,082 & 0.010427227 & 0.009579155 & 0.020006381 & $156,049.77$ & 15 \\
\hline D2 & 800 & 63,017 & 0.00724113 & 0.017711683 & 0.024952813 & $194,631.94$ & 12 \\
\hline D3 & 608 & 23,103 & 0.005503259 & 0.006493375 & 0.011996634 & $93,573.74$ & 20 \\
\hline D4 & 624 & 9,599 & 0.005648081 & 0.002697914 & 0.008345995 & $65,098.76$ & 21 \\
\hline D5 & 1,552 & 63,105 & 0.014047791 & 0.017736417 & 0.031784208 & $247,916.82$ & 10 \\
\hline D6 & 80 & 2,963 & 0.000724113 & 0.000832787 & 0.0015569 & $12,143.82$ & 26 \\
\hline D7 & 1,664 & 29,175 & 0.01506155 & 0.008199983 & 0.023261533 & $181,439.96$ & 13 \\
\hline D8 & 2,128 & 29,893 & 0.019261405 & 0.008401786 & 0.027663191 & $215,772.89$ & 11 \\
\hline D9 & 9,064 & 95,940 & 0.082041999 & 0.026965087 & 0.109007086 & $850,255.27$ & 3 \\
\hline D10 & 5,600 & 148,456 & 0.050687907 & 0.041725338 & 0.092413246 & $720,823.32$ & 5 \\
\hline D11 & 2,928 & 64,494 & 0.026502534 & 0.018126812 & 0.044629346 & $348,108.90$ & 8 \\
\hline D12 & 5,912 & 148,506 & 0.053511948 & 0.041739391 & 0.095251339 & $742,960.45$ & 4 \\
\hline D13 & 7,920 & 148,593 & 0.071687183 & 0.041763844 & 0.113451027 & $884,918.01$ & 2 \\
\hline D14 & 4,336 & 186,681 & 0.039246923 & 0.052468933 & 0.091715855 & $715,383.67$ & 6 \\
\hline D15 & 6,728 & 187,008 & 0.0608979 & 0.05256084 & 0.11345874 & $884,978.17$ & 1 \\
\hline D16 & 2,000 & 100,587 & 0.018102824 & 0.028271182 & 0.046374006 & $361,717.25$ & 7 \\
\hline D17 & 416 & 133,859 & 0.003765387 & 0.037622677 & 0.041388064 & $322,826.90$ & 9 \\
\hline D18 & 160 & 53,637 & 0.001448226 & 0.015075322 & 0.016523548 & $128,883.67$ & 17 \\
\hline D19 & 160 & 7,588 & 0.001448226 & 0.002132698 & 0.003580924 & $27,931.21$ & 24 \\
\hline $\mathrm{D} 20$ & 64 & 10,008 & 0.00057929 & 0.002812868 & 0.003392159 & $26,458.84$ & 25 \\
\hline $\mathrm{D} 21$ & 256 & 67,025 & 0.002317161 & 0.01883818 & 0.021155341 & $165,011.66$ & 14 \\
\hline D22 & 224 & 53,569 & 0.002027516 & 0.01505621 & 0.017083726 & $133,253.06$ & 16 \\
\hline D23 & 192 & 46,322 & 0.001737871 & 0.013019353 & 0.014757224 & $115,106.35$ & 18 \\
\hline D24 & 32 & 1,871 & 0.000289645 & 0.000525867 & 0.000815512 & $6,360.99$ & 27 \\
\hline $\mathrm{D} 25$ & 32 & 16,092 & 0.000289645 & 0.004522849 & 0.004812495 & $37,537.46$ & 23 \\
\hline D26 & 512 & 27,352 & 0.004634323 & 0.007687607 & 0.01232193 & $96,111.06$ & 19 \\
\hline \multirow[t]{2}{*}{$\mathrm{D} 27$} & 96 & 26,442 & 0.000868936 & 0.007431841 & 0.008300777 & $64,746.06$ & 22 \\
\hline & 55,240 & $1,778,967$ & 0.5 & 0.5 & $100 \%$ & $7,800,000$ & \\
\hline
\end{tabular}




\subsection{The use rapid result approach}

The Rapid Result Approach (RRA) was introduced to Community Based Rural Development Project (CBRDP) by Robert H. Schaffer \& Associates (RHS\&A) in 2006. CBRDP has since facilitated the use of RRA by Communities, Area Councils and District Assemblies in executing projects.

The main objective of Rapid Result Approach is aimed at jump-starting major change effort and enhancing implementation capacity. A Rapid Result Approach is also a planned effort designed to stimulate group adrenalin by galvanizing a team around the achievement of a meaningful, challenging results in a short period of time. This is done through the formation of groups and teams.

This approach was used under Northern Floods Reconstruction Programme (NFRP) in reconstructing some of the damage infrastructure. Changed agents formed were the Coach, Group leader, Strategic leader, Team leader and Team members.

This approach was used to reconstruct a damaged infrastructure within 100 days. The community under the supervision of Area Councils and District Assembly organized themselves for the reconstruction of the damaged facilities.

\section{Challenges}

\subsection{Inadequate funding}

The funds available was less than $10 \%$ of what was actually needed to effectively repair the damaged infrastructure caused by the 2007 flash floods that

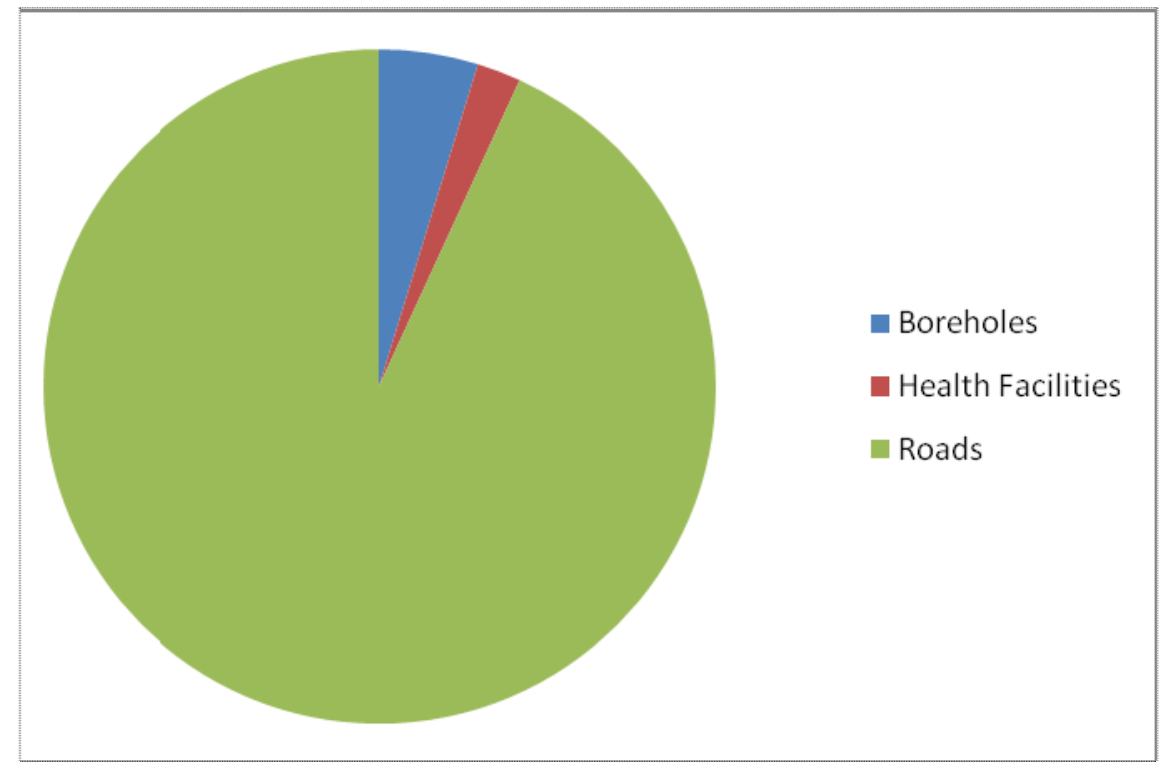

Figure 3: Percentage distribution of infrastructure repaired. 
affected the northern part of Ghana. This posed a great challenge in the implementation of the programme. Some of the interventions proposed by some DAs were not adequate to address the problems caused by the floods. This was as a result of inadequate funds allocated to the districts.

\section{Distribution of infrastructure destroyed}

Various types of infrastructure were destroyed by the 2007 northern floods. However, only eligible projects under the World Bank funded CBRDP and IFAD funded NORPREP were repaired or worked on. With these criteria, the types of infrastructure that were eligible included water facilities, health facilities and road infrastructure. The distribution of infrastructures that were repaired after the intervention is as indicated in figure 2. This distribution resulted from the cumulative funds spent on the damaged infrastructure, which was proportional to the number affected.

\subsection{Rules and regulations of sector agencies}

The use of existing institutions proved successful in the implementation of the programme. However, coordinating the rules and regulations of individual institutions created a big challenge in the implementation.

\subsection{Abuse of procurement procedures by some DAs}

Although stringent measures were put in place to ensure that no abuse of procurement procedures, some DAs nonetheless went against the tenets of Ghana procurement Act, 663 and World Bank procurement guidelines and had to be corrected. It must be emphasized this was on minor scale.

\subsection{Monitoring}

There was the need for constant and regular monitoring of the implementation process by the implementation agencies to ensure quality of work and to meet deadlines. Considering the fact that these projects were scattered in 29 districts of the three northern regions made monitoring very expensive and challenging.

\section{Lessons learnt}

A lot of useful lessons could be learnt from the implementation of the Northern Floods Reconstruction Programme in Ghana, which could be particularly useful for similar programmes in other developing countries. Some of the major lessons learnt are:

\subsection{The use of existing structures}

The use of existing recognized institutions and bodies facilitated the implementing of Ghana's Northern Flood Reconstruction Programme (NFRP). 
No new parallel structures were created. This helped in the maximization of resources and made the implementation of the programme reasonably smooth. Considering the emergency nature of such programmes it would be very beneficial if existing structures are employed in future programmes instead of creating new ones.

\subsection{Meeting the needs of the people}

The design of the programme took into consideration the major specific impacts of the floods on affected communities and districts. The initial inclusion of beneficiary district assemblies and communities in the identification of damaged infrastructure and the required interventions created an integrated approach in the implementation of the programme. This integral approach increased the communities' willingness to participate in the programme. It will be useful for future flood reconstruction programmes if the major needs of local communities are included in the fundamental objectives of the programme.

\subsection{Participation of stakeholders}

Full participation of community members is very essential for a successful integrated programme, this confirms the assertion by Rosenfield and Wilson. The involvement of community members at the very beginning of the programme helped in tapping their indigenous knowledge, which aided local members to consider themselves as partners of the programme.

\subsection{The use of effective organizational structure}

A proper organizational structure is very important in such integrated programme. This helps in clear representation and understanding of roles and responsibilities of stakeholders. Duplication of activities and conflicts are avoided or reduced when proper organizational structures are put in place.

\section{Conclusion}

The experience of the Northern Floods Reconstruction Programme implemented by the Ghana Government through the CBRDP suggests that, despite the constraints, which complicate the implementation of such emergency programmes, potential exists for effective implementation of such programmes if they are carried out in an integrated manner. It demonstrates that stakeholderbased participation is crucial in organising and managing such programmes. By identifying all stakeholders involved and ensuring their active participation can avoid power struggle among existing structures and thus perpetuating conflicts between elite stakeholders and local communities. The use of existing institutions/agencies instead of creating new ones speed up implementation process and ensuring early completion of such projects, this according to Banga and Sharma, are critical in emergency situations. 


\section{References}

[1] Ghana Inter-ministerial Relief Committee and United Nations Team in Ghana, Joint Assessment Report on 2007 Flash Floods in Northern Ghana.

[2] Ghana local government Act 462, 1987

[3] Decentralization Policy Framework (2010); Accelerating Decentralization and Local Government for National Development. Ghana National Decentralization Plan, pp 3-21

[4] Community Based Rural Development Project (CBRDP), Annual Report, 2008

[5] Ghana public procurement Act, 663, 2003

[6] World Bank, Guidelines procurement under IBRD loans and IDA credits, 2010

[7] Community Based Rural Development Project (CBRDP); 2007 Northern Flash Floods Assessment report pp. 45-49, 2007.

[8] Rosenfield, R.H. \& Wilson, D.C. Managing Organizations, Text, Reading \& Cases Mc Graw Hill, pp 82-84

[9] Schied, T.D. \& Collins L, Disaster management and preparedness. Occupational safety and health guide series, pp. 23-25, 2008

[10] Banga, T.R. \& Sharma, S.C. Industrial Organization and Engineering Economics. (327-340), 1992.

[11] www.practicalaction.org/Disasters 